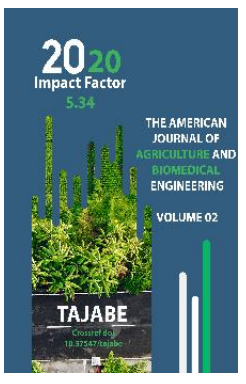

Journal Website: http://usajournalshub.c om/index,php/tajabe

Copyright: Original content from this work may be used under the terms of the creative commons attributes 4.0 licence.

\section{Culture And Use Of Trichogramma Ostriniae Species Against Corn Motor Eggs}

\author{
B.B.Sobirov \\ Scientific Center For Plant Quarantine Of The State Plant Quarantine Inspection Under The \\ Cabinet Of Ministers Of The Republic Of Uzbekistan, Tashkent, Uzbekistan.
}

\section{O.A.Sulaymonov}

Scientific Center For Plant Quarantine Of The State Plant Quarantine Inspection Under The Cabinet Of Ministers Of The Republic Of Uzbekistan, Tashkent, Uzbekistan.

\author{
A.R.Anorbaev \\ Tashkent State Agrarian University, Tashkent, Uzbekistan. \\ R.A.Jumaev \\ Tashkent State Agrarian University, Tashkent, Uzbekistan.
}

\title{
ABSTRACT
}

The article discusses the issue of mass breeding in the biological laboratory of the ovarian parasite of the corn moth - trichogramma, in particular, the species Trichogramma ostriniae, widely represented in the nature of Uzbekistan.

\section{KEYWORDS}

Biological method, biolaboratory, corn moth, trichogramma, mother material, sitotrog.

\section{INTRODUCTION}

The larva of the corn moth (Ostrinia enubilalis $\mathrm{Hb}$ ) damages corn buds as well as corn cobs, tomato fruits, pea kernels and many other crops. Affected corn buds and young bolls fall off, which greatly affects the overall yield. In the conditions of Central Asia and the Caucasus, the first mass years of corn moth butterflies coincides with the time of formation of corn moth ovaries and falls on average from May 20 to June 20. At average monthly temperatures equal to $200 \mathrm{C}$, the development of the pest takes 28-35 days. To combat boxworm, various methods are currently used, in particular, agrotechnical, chemical and others. Farmers in Uzbekistan widely use the biological method, which has proven to be highly effective and is the most economically viable. The main natural enemies of the corn moth from the pest are: trichogramma, apanteles, poacher, tahina flies and some other representatives of the insect world. In total, more than 45 species of the parasites Trichogrammatidae naturally 
occurring in the order Hymenoptera are known in the corn-growing regions.

In the system of protection of the corn crop, great importance is attached to the parasite Trichogramma ostriniae. Trichogramma, in particular, a species widely represented in the nature of Uzbekistan, which belongs to the representatives of the family. Trichogrammatidae, order Hymenoptera. Insects belonging to this family of chalcides, despite their small size $0.12-1.2 \mathrm{~mm}$, are considered ovarian parasites of scoops, moths and many other harmful lepidopteran pests, because develop inside their eggs. Unlike larvae, adults feed on the nectar of flowers. It hibernates in the phase of adult larvae in the eggs of various lepidopteran pests, where it later turns into a pupa and then, gnawing through the shell, flies out in the form of an imago. After mating, begins to lay eggs.

\section{RESEARCH METHODS AND MATERIALS}

Trichogramma ostriniae are small insects (0.4$0.6 \mathrm{~mm}$ ), light brown to black. The forewings are wide with cilia, 2 times as long as the wing width. Males are similar to females, only the antennae of the female are 5-segmented, in contrast to the 3-segmented antennae of the male. In agrobiocenoses, they are found on crops of corn, cotton, tomatoes and other agricultural crops. It is considered one of the main entomophages in the protection of crops from harmful butterflies, because guided by the smell of the pest, it lays 1-2 of its eggs in the eggs of the pests in which it further develops, feeding on the internal contents. On average, one female can lay 4560 eggs. Biological efficiency is $65-70 \%$. Optimal conditions for development are: temperature within the range of $20-33^{\circ} \mathrm{C}$ at a relative humidity of $75-90 \%$. In the population, the number of females is greater and amounts to $75-90 \%$. In the conditions of Uzbekistan, it gives 10-12 generations. An adult insect lives on average for 4-6 days, when the temperature drops to $10-11^{\circ} \mathrm{C}$, it hibernates.

Trichogramma breeding technology in the biolaboratory. Proven technology, in order to obtain the required quantity of high-quality products - trichogramma in conditions of distribution in biolabs, it is necessary to have a supply of mother material. Mother material includes biological material collected in nature, which includes the collection of scoop eggs infected with trichogramma. Collection of mother material begins in August and continues until January-February. The production of mother material includes separate stages:

1. Collecting natural trichogramma in the fields,

2. Growing eggs scoop,

3. Cultivation of Trichogramma mother material, 

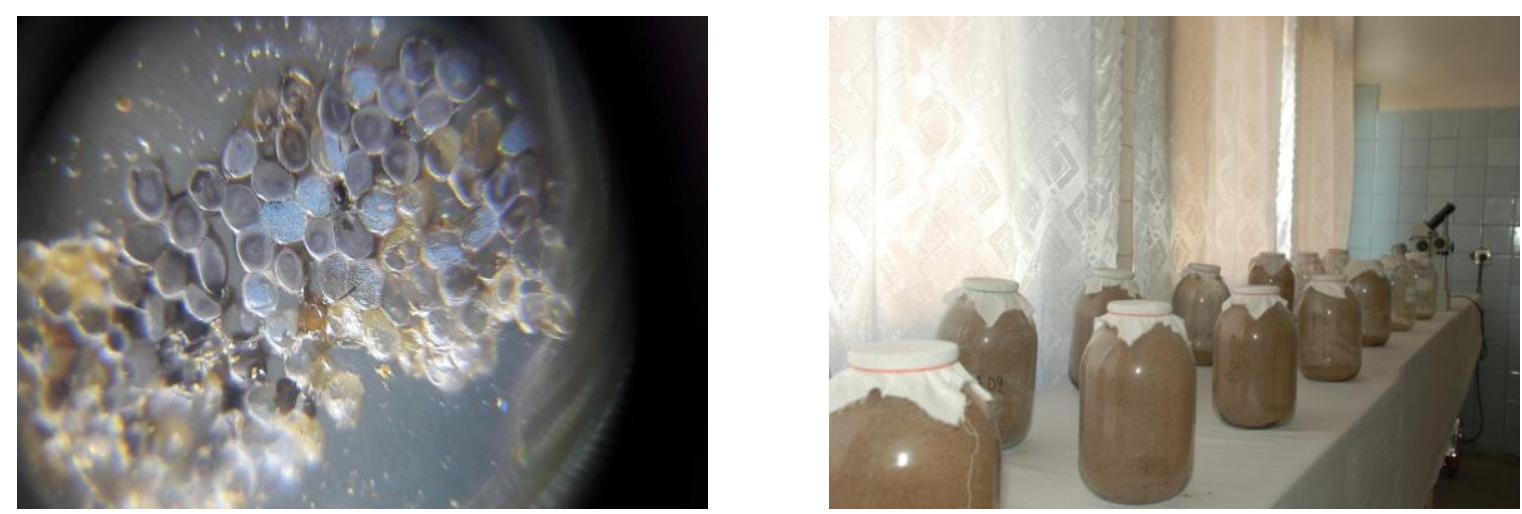

Fig-1. Bulk rearing in laboratory conditions of moth eggs infected with trichogramma

(Figure: H. Kimsanboev)

\section{RESEARCH RESULTS AND THEIR DISCUSSION}

Growing moth eggs - natural hosts of trichogramma. To obtain the mother material of Trichogramma, it is necessary to pass it through cultivation in a biological laboratory in the eggs of natural hosts in the autumn and winter periods.

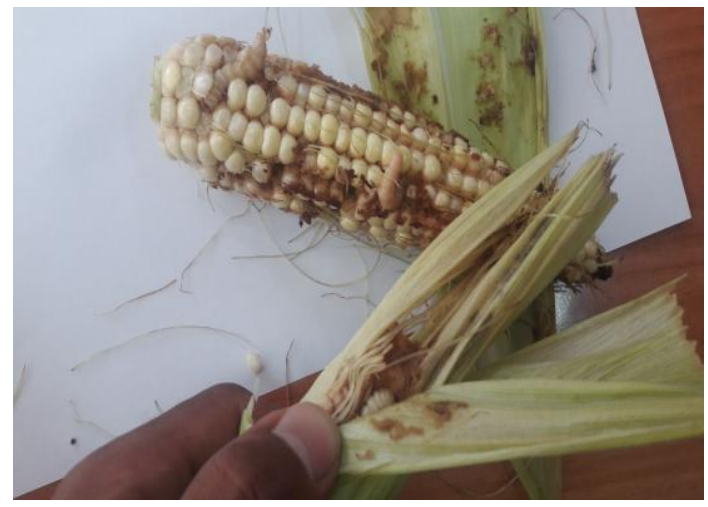

To obtain pest eggs, moths, butterflies or scoop pupae are grown in a biolaboratory, collected in nature by various methods (for example, with light traps). One of the directions of obtaining eggs from butterflies of natural hosts is their breeding in a biolaboratory in artificial or natural environments.

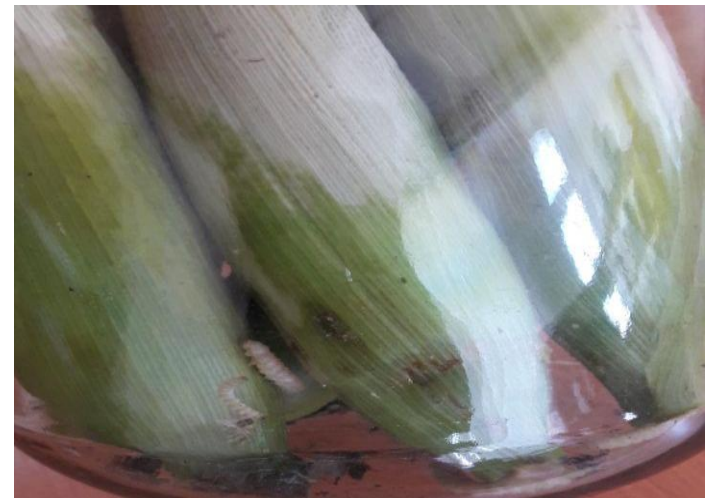

Fig. 2 Mass rearing of the corn moth larva in laboratory conditions

(Fig: B. Sobirov).

To do this, males and females of scoop butterflies collected in nature are mixed in glass containers of 8-10 individuals. To collect further pest eggs, accordion-folded paper is laid inside the jar. To feed the butterflies, a cotton wool soaked in $20 \%$ sugar syrup is 
placed on the bottom of the can. Banks are covered with gauze, which is fixed with a rubber ring. Banks are stored at a temperature of $20-25^{\circ} \mathrm{C}$ and a relative humidity of $65-70 \%$. Banks are reviewed daily with the collection of laid eggs and deceased individuals, which are replaced with fresh ones.

Obtaining the mother material of trichogramma from moth eggs. Trichogramma collected in nature is stored in a wide-necked 1 liter glass container covered with a dense cloth on top. To feed the trichogramma, a cotton wool soaked in 10\% sugar syrup is placed on top of the fabric. The grown eggs of natural hosts are laid inside. When the ratio of males and females is $1: 20$, mating occurs. Banks are stored in the light at a temperature of $24-25^{\circ} \mathrm{C}$ and a relative humidity of $70-75 \%$. After 5-7 days, the infected eggs turn black and are laid out from the container, replacing them with new, uninfected eggs. The change of lots of eggs is carried out 3-4 times. In this way, the uterine population of Trichogramma is obtained.

\section{Table 1.}

\section{Efficacy of Trichogramma ostrinia Against Pest Eggs Under Laboratory Conditions}

\begin{tabular}{|c|c|c|c|}
\hline \multirow{2}{*}{ Pests } & \multicolumn{3}{|c|}{ Efficiency, \% } \\
\cline { 2 - 4 } & $\mathbf{2 8}^{\circ} \mathbf{C}, \mathbf{7 0 - 8 0 \%}$ & $\mathbf{3 0}^{\circ} \mathbf{C}, \mathbf{7 0 - 8 0 \%}$ & $\mathbf{3 5}^{\circ} \mathbf{C}, \mathbf{7 0 - 8 0 \%}$ \\
\hline Corn moth & 78.2 & 86.5 & 63.1 \\
\hline Cotton scoop & 79.1 & 84.3 & 61.2 \\
\hline Grain moth & 76.6 & 83.9 & 57.8 \\
\hline
\end{tabular}

So, diagram No. 1 shows the growth of the area of application of the biological method in the fight against agricultural pests since 2017 when it amounted to 15308.7 thousand hectares, taking into account the frequency of application, in 2018 its growth is visible to 17231.2 thousand hectares, which reached $22,543.6$ thousand hectares in 2019, and in 2020 its maximum value of $25,260.6$ thousand hectares was reached, taking into account the frequency of application.

Getting a trichogram. Trichogramma obtained from the uterine population in a massive way in the biological laboratory is the final product and is used in crops to control harmful Lepidoptera.

The mother material of the Trichogramma in the biolaboratory is propagated for 4-5 cycles on the eggs of the grain moth (sitotrogi).

For withdrawal from diapause, 2-3 g of Trichogramma stored in the refrigerator is placed in glass jars, which are stored at a temperature of $25-26^{\circ} \mathrm{C}$ and a humidity of $75^{-}$ $80 \%$. After 3-6 days, the trichogramma years begins. To feed the trichogramma, a cotton swab soaked in $20 \%$ sugar syrup is placed on top of the cloth covering the can. 

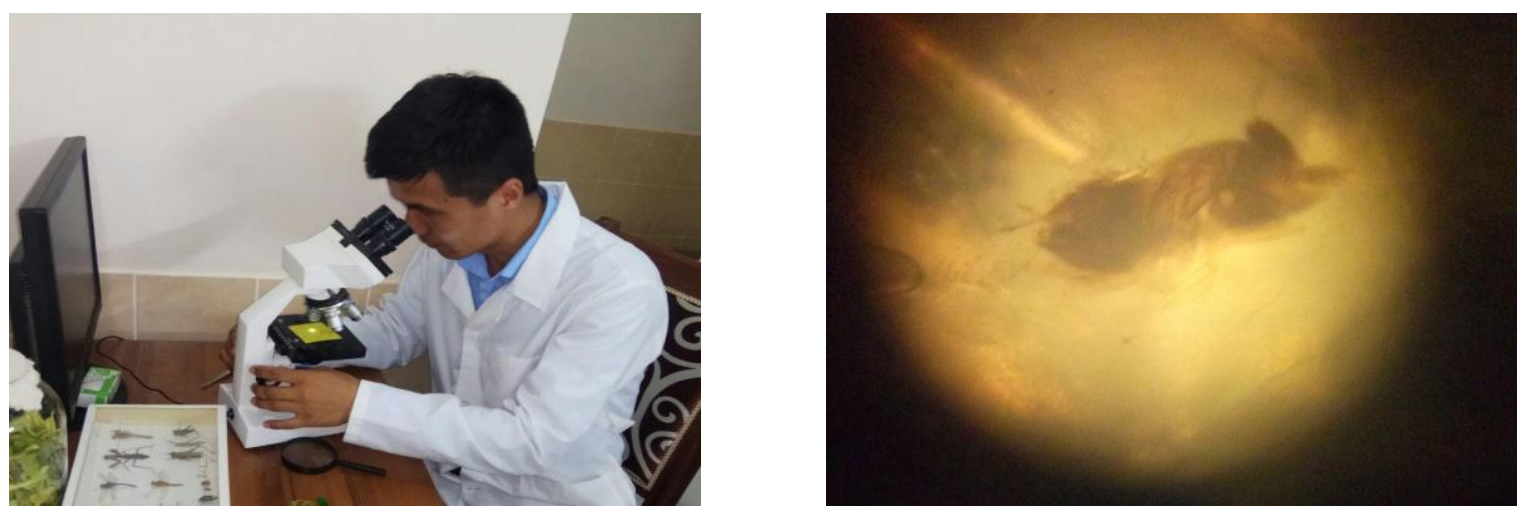

Fig. 3 Conducting experiments on breeding Trichogramma.

(Rice: B. Sobirov).

To obtain a commercial trichogram, it is necessary to cultivate it on the eggs of a laboratory host - a grain moth. To do this, the cleaned $3 \mathrm{I}$ jars are "steamed" and dried, then in a circular motion the jars are laid inside the jars grown in the biological laboratory. Then on the eggs of the grain moth adhered to the inside of the jar, the mother material of Trichogramma is released. The banks indicate the number of eggs laid by the sitotroga and the released trichogramma. Lighting is required to obtain a commercial trichogram.

After 5-6 days, the eggs of the grain moth, embedded inside the jar, infected with trichogramma, darken and with a soft brush are collected in paper bags indicating the collected mass. If it is impossible to immediately use sitotrog eggs on crops infected with trichogramma, they can be stored for a short time in household refrigerators at a temperature of $1-30 \mathrm{C}$ and a humidity of $80-90 \%$.

For a highly effective use of the commercial trichogram obtained in the biolaboratory, it is necessary to observe the technology of its dilution. So, in the trichogramma production shop, the temperature should be kept within $25-30^{\circ} \mathrm{C}$ during the day, $18-20^{\circ} \mathrm{C}$ at night with $60-70 \%$ humidity. Trichogramma is fed daily with $20 \%$ sugar syrup, occasionally supplemented with pure water.

The first dispersal of Trichogramma in the fields coincides with the moment of laying eggs by pests. The terms of colonization are determined by long-term forecasts and on the basis of data on the number determined by pheromone traps.

\section{CONCLUSIONS AND SUGGESTIONS}

Infection of corn moth eggs in the field is observed in 5-8 days. After 10-12 days, the effectiveness of infection of the pest's eggs is reduced by 4 times, and after 15 days, it is not observed at all. Therefore, for effective protection of the crop, a 3 -fold release of the biomaterial of the entomophage is necessary. So, $0.5+0.75+0.5 \mathrm{~g}$ (or $30+50+30$ thousand pieces) of trichogramma are settled per 1 hectare, for corn crops the ratio is $60+$ 
$80+60$ thousand pieces (total 200 thousand)

...

The first colonization with trichogramma is performed after 5- 6 days when 3-4 corn moth butterflies are detected by pheromone traps per day. The second and third time 3-4 days after detecting 1.2 moths per day. It is necessary to pay attention to the uniform distribution of the biomaterial. To do this, trichograms, ready to emerge from the infected moth eggs, are laid out in a new way on the trichocard, then 100 pieces are laid out there. folded $1-1.5 \mathrm{~cm}$ of scraps of paper on which emerged individuals of the entomophage settle. Trichogramma is released early in the morning (at 6-11 o'clock), or in the evening (from 18-20 o'clock) on the shaded leaves of the lower or middle tier of plants. On 1 hectare, Trichogramma is settled in 100 places (according to the scheme 10x10 $\mathrm{cm})$.

\section{REFERENCES}

1. Anorbaev A.R. Application of trichogram in trichocards in the control of the number of harmful tsunamis and its effectiveness // Proceedings of the scientific-practical conference "Agrotechnological problems of agricultural engineers". - Nukus, 2012. - P. 39-42.

2. Bondarenko N.V. Biological plant protection. - M .:, Agropromizdat, 1986.

3. Djumaev R.A.In vitro rearing of trichogramma (Hymenoptera: Trichogrammatidae) // European Science Review № 9-10. Austria, Vienna 2016. -P. 11-13.

4. Kimsanbaev Kh.Kh., Sulaimonov BA, Rashidov MI, Boltaev BS. The basics of insect reproduction in the biolaboratory and their application against cotton pests. - Tashkent, 2007 - 4 p. (uzb.)
5. Kimsanboev Kh.Kh., Anorbaev A.R., Sulaymonov O.A. Study of the effectiveness of using the introduced species Trichogramma chilonis Ishii in the cotton biocenosis // The role and importance of the development of innovative science and education in the development of a harmoniously developed generation. Scientific-practical conference. Book 1. - Tashkent, 2014. - P. 334-336.

6. Sulaymonov O.A., Sobirov B.B, Saipieva D.K. Study of storage and survival of Trichogramma ostriniae // Eurasian Union of Scientists (ESU). - 2020. - P. 29-30.

7. Sulaymonov O.A., Sobirov B.B. Bioecology of stem corn mother (ostrinia nubilalis hb) and accounting of its parasitic entomophages / Proceedings of International Multidisciplinary Scientific Conference on Innovative Technology Organized by Novateur Publications, India May 25th, 2020. P. 156-160. 